\section{Antagonistic Effect by Certain Growth- Stimulants of the Tuberculostatic Activity of 5-Amino-2-butoxypyridine}

THE powerful inhibitory action of 5-amino-2. butoxypyridine on the growth of Mycobacteria, which is highly specific for members of that genus, has recently been reported ${ }^{1,2}$. Strains of $M$. tuberculosis (including the human-type $H 37 R v$ ) and $M$. phlei were inhibited at dilutions of this compound so high as 0.03-0.001 mgm. per cent in Dorset's synthetic or in Proskauer-Beck medium, inoculation being either on the surface by a small piece of pellicle or by a suspension of about 20,000 organisms per $\mathrm{ml}$.

As we had immediate access to the compound, in the form of the dihydrochloride, we have sought independent confirmation of these remarkable observations. We have used H37Rv (from the American depot at Trudeau Sanatorium, Saranac Lake) and a bovine-type strain $S B$ (from Mr. R. E. Glover) as examples of $M$. tuberculosis, as well as a laboratory strain $(P)$ of $M$. phlei. Growth was completely or almost completely inhibited at drug concentrations of less than $0.1 \mathrm{mgm}$. per cent under the following conditions :

(i) Surface culture of $H 37 R v$ in Proskauer-Beck medium, and of $P$ in digest broth and in a modification of the synthetic basal medium of Dubos ${ }^{3}$ (Difco Casamino acid, $2.5 \mathrm{gm}$.; asparagine, $0.3 \mathrm{gm}$.; anhydrous $\mathrm{Na}_{2} \mathrm{HPO}_{4}, 2.5$ gm.; $\mathrm{KH}_{2} \mathrm{PO}_{4}, 1.0 \mathrm{gm}$. ; sodium citrate, $1.5 \mathrm{gm}$.; $\mathrm{MgSO}_{4}, 7 \mathrm{H}_{2} \mathrm{O}, 0.6 \mathrm{gm}$.; glycerol, $25 \mathrm{ml}$; distilled water to 11 .);

(ii) Sub-surface culture of $H 37 R v, S B$ and $P$ in the synthetic basal medium, and of $H 37 R v$ in ProskauerBeck medium, the inoculum being $0.04 \mathrm{mgm}$. moist weight of bacilli per $5 \mathrm{ml}$. medium in a $25 \mathrm{~mm}$. diameter test-tube; $M$. tuberculosis surface cultures were read at 30 days, and sub-surface cultures at 14 days; $M$. phlei surface and sub-surface cultures were read at 4 days. In these findings we are in agreement with the American workers.

Addition of 0.25 per cent serum albumin (bovine plasma fraction $V$ ) to the Proskauer-Beck medium and to the broth had no apparent effect on the marked inhibition of growth of surface-cultured $H 37 R v$ and $P$, respectively. Such addition to the synthetic basal medium carrying a surface transplant of $P$ resulted in some delayed surface growth in the higher dilutions of the compound where there had been complete inhibition in the absence of albumin, and, moreover, growth was noted in the depth of the medium even at a drug concentration of $20 \mathrm{mgm}$. per cent.

The conditions governing the bacteriostatic activity of aminobutoxypyridine in sub-surface culture were, therefore, examined more closely. It was found that, in sub-surface culture, its inhibitory effect against $H 37 R v, S B$ and $P$ in the synthetic basal medium was considerably reduced by the addition of albumin, substantial granular growth, or diffuse growth in the case of $P$, being evident at the highest drug concentration tested (10 mgm. per cent). This antagonistic effect is not specific to albumin, since a similar result was obtained if the latter was replaced by the nonionic synthetic detergent 'Tween 80' (a polyoxyethylene derivative of sorbitan mono-oleate) at 0.05 per cent ; this product is known for its marked stimulating and dispersing effect on the growth of Mycobacteri $a^{3}$. The simultaneous addition of albumin and 'Tween 80 ' led to total, or almost total, abolition of inhibition of the three strains over the range of drug concentration tested $(10-0 \cdot 1 \mathrm{mgm}$. per cent), profuse diffuse growth occurring at $10 \mathrm{mgm}$. per cent. To test the possibility that some constituent of the synthetic basal medium might be a factor, these experiments were repeated with $H 37 R v$ in the Proskauer-Beck medium; the bacteriostatic effect shown in the medium alone over the range of drug concentrations, $10-0.1 \mathrm{mgm}$. per cent, was totally abolished by the addition either of albumin, or of 'Tween 80', or of both. Finally, the effect of reducing the inoculum was examined; with $1 / 100$ the usual inoculum of $H 37 R v$ and $1 / 1,000$ that of $P$, the inhibition previously observed was evident in the synthetic basal medium, but definite growth was again noted in the tubes containing albumin, or albumin and 'Tween 80', and the drug at a concen. tration of $10 \mathrm{mgm}$. per cent.

Certain factors or combinations of factors can, therefore, antagonize to a marked degree the inhibitory effect of aminobutoxypyridine on the growth of Mycobacteria. This antagonism can be observed in sub-surface culture when carried out in the presence of serum albumin or of certain growth-stimulating lipids. The antagonistic effect of serum albumin was surprising in view of the fact that Feinston $\theta^{1}$ has stated that the tuberculostatic activity of the drug was not antagonized by up to 25 per cent of whole blood or serum. The present findings have an unfavourable bearing on the possibility of this substance proving a useful chemotherapeutic agent. It should be added that both streptomycin and licheniformin show clear inhibitory end-points under the conditions of sub-surface culture in the Dubos albumin-"Tween 80 ' medium described here.

\section{H. S. Forrest \\ P. D'ARCy HaRT \\ JAMES W ALKER}

National Institute for Medical Research, Hampstead, London, N.W.3. April 23.

${ }^{1}$ Feinstone, W. H., Proc. Soc. Exp. Biol., N.Y., 63, 153 (1946).

'Feinstone, w. H., Friedman, H. L., Rothlauf, M. V., Kelly, A. M., and Williams, R. D., J. Pharmacol., 89, 153 (1947).

'Dubos, R. J., and Davis, B. D., J. Exp. Med., 83, 409 (1946).

\section{Sex Reversal in Patella coerulea L. and Diodora gibberula (Lam.)}

CREwE ${ }^{1}$ has recently discussed the possible influence of helminth parasites on sex determination in limpets. Following the earlier observations of Orton ${ }^{2}$, I have been studying the problem of sexuality in the Mediterranean limpet Patella coerulea L., both statistically and histologically. In contrast to the conditions in Patella vulgata, no larval Trematodes have been observed in several thousands of $P$. coerulea which I have examined. These parasites must therefore be at most extremely rare in the present populations of Patella in the Bay of Naples.

My statistical observations with $P$. coerulea, represented graphically in the appended diagram, show the sex proportions in different size-classes in the months November, January and March. The total numbers examined are given : fuller numerical details will be published elsewhere.

The data available permit the following conclusions to be drawn : $(a)$ most individuals of $P$. coerulea undergo sex inversion from the male to the female phase as they grow older; (b) a small proportion seem to be determined as females from the beginning of sexual differentiation; (c) a small proportion remain as males throughout life; (d) sex inversion may occur in any size class; (e) the rate of sex inversion does not keep pace with the rate of increase; this fact is made evident by the shift in the point of 